\title{
OLHARES FOTOGRÁFICOS, MEDIAÇÕES E EXPRESSÕES DO LUGAR: EXPERIMENTAÇÕES COM ALUNOS DO ENSINO BÁSICO DE FEIRA DE SANTANA- BA
}

\author{
CAMILA MACHADO PAIM'
}

1.Bolsista Pevic-Uefs, Graduanda de Licenciatura em Geografia, Universidade Estadual de Feira de Santana, email: camila.paim.754@gmail.com

\section{CLÉA CARDOSO DA ROCHA ${ }^{2}$}

2. Orientadora, Departamento de Educação, Universidade Estadual de Feira de Santana, email: cleabase@yahoo.com.br

PALAVRAS CHAVES: LUGAR; FOTOGRAFIA; ENSINO DE GEOGRAFIA.

\section{INTRODUÇÃO}

Este plano de trabalho teve por finalidade compreender a formação do conceito de lugar por alunos do ensino fundamental II, de escolas públicas de Feira de Santana, através da educação do olhar e produção de fotografias como recurso didático-pedagógico. Para tanto, promoveu-se atividades de intervenção em uma escola básica da rede pública, localizada no município de Feira de Santana-BA, que atende ao público do $6^{\mathrm{a}}$ ao $9^{\mathrm{a}}$ ano do ensino fundamental II, a faixa etária dos alunos está entre 10 e 15 anos de idade.

Cabe salientar que foi necessário fazer duas intervenções, entre o ano de 2016 e 2017, com turmas do $6^{\mathrm{a}}$ ano, visto que na primeira não foi possível atingir os objetivos propostos nesse plano de trabalho, pois não foi realizada a oficina de fotografia por conta do tempo curto disponibilizado pela escola. Este plano foi desenvolvido em conjunto com o plano de trabalho: "Narrativas autobiográficas sobre o lugar: significação e construções de saberes, vivências e afetividades de alunos da educação básica de Feira de Santana - BA".

A primeira intervenção ocorreu quase no final do ano letivo durante três dias no final do mês de novembro e início de dezembro, a turma escolhida foi uma do sexto ano, com 20 alunos com idade entre 11 a 15 anos. É importante destacar, que dois alunos são portadores de necessidades especiais e, portanto, as atividades precisaram ser diferenciadas, principalmente na aplicação do questionário (sendo utilizados desenhos para responder algumas questões), esses alunos também deixaram de produzir a fotografia visto que precisavam do auxílio das famílias de ambos e não houve colaboração neste sentido. Na primeira etapa, foi levantado, inicialmente, o conceito prévio dos alunos sobre o lugar e foi aplicado um questionário. Já na segunda etapa, foi reforçado o conceito de lugar, a partir das concepções de autores como Carlos (1995) e Tuan (1983), além de fotografias de diferentes lugares. Sendo que esses autores discutem o lugar na perspectiva do espaço vivido pelo sujeito.E por fim, na terceira etapa, foi realizada uma "exposição" com as fotografias e textos trazidos pelos alunos, onde puderam falar sobre o que para eles constituía-se um lugar através das suas produções, e também, sobre o que foi apreendido durante os dois dias da intervenção.

A segunda intervenção aconteceu no ano de 2017, e novamente com uma turma do sexto ano, com 17 alunos de idade entre 11 a 14 anos, dentre estas, mais uma vez encontramos duas alunas portadoras de necessidades especiais, indicando a escola como um espaço inclusivo. As atividades foram desenvolvidas em quatro dias com quatro etapas. A mesma, seguiu os passos da intervenção anterior, com o diferencial do desenvolvimento da oficina de fotografia na terceira etapa.Assim, discutiu-se a fotografia e a construção do olhara 
partir de conceitos de autores como: Dubois (1993), Samaim (2005) que procura definir a fotografia como servidora da memória abarcando a relevância do conteúdo contido na mesma e Alves (2012) discute o olhar, ou melhor, o saber olhar com qualidade, no caso especial da fotografia.Ainda nesse encontro foi solicitado a produção de uma fotografia (cada um) sobre seus lugares como o intuito de montarmos um painel para a exposição na aula seguinte. $\mathrm{Na}$ quarta etapa realizou-se a exposição com as fotografias dos alunos.

\section{MATERIAIS E MÉTODOS}

Para que esse projeto fosse desenvolvido utilizou-se métodos que estão de acordo com o projeto de pesquisa "Lugar: Formação Docente e Elaboração de Material DidáticoPedagógico Sobre Feira de Santana/BA", pesquisa de caráter qualitativo e colaborativo. Assim as seguintes atividades desenvolvidas no decorrer da pesquisa foram: Levantamento bibliográfico sobre os temas chave (Lugar, imagem, fotografia, olhar e ensino geográfico); Discussão teórica com grupo Lugar; Visitação às escolas; Orientação aos alunos para produção das fotografias e discussão do olhar através de uma oficina; Exposição das fotografias por parte dos alunos;Sistematização e interpretação dos dados;Análise dos resultados obtidos para: auto avaliação/reflexão e construção de relatórios para participação de eventos e publicação dos resultados.

\section{RESULTADOS}

Apresentam-se a seguir uma síntese da análise dos questionários e as fotografias produzidas com análise nas duas intervenções respectivamente.

Turma 1- A partir das respostas do questionário observou-se que os alunos compreendiam lugar como espaço, ambiente, ligados ao lazer ou segurança, aparentemente sem muita relação com eles. Apenas um aluno referiu-se a lugar como lugar de vivência. Observou-se também que nenhum deles apontou Feira de Santana como seu lugar, apesar de relatarem, na sua maioria que relaciona-se bem com a cidade onde moram. Já a partir da análise das fotografias (figura 1), produzidas foi possível observar que o conceito de lugar mudou principalmente, no que se refere ao olhar do aluno sobre Feira de Santana como seu lugar após as discussões em sala de aula. O lugar foi reafirmado como aquele das suas relações, não algo abstrato.

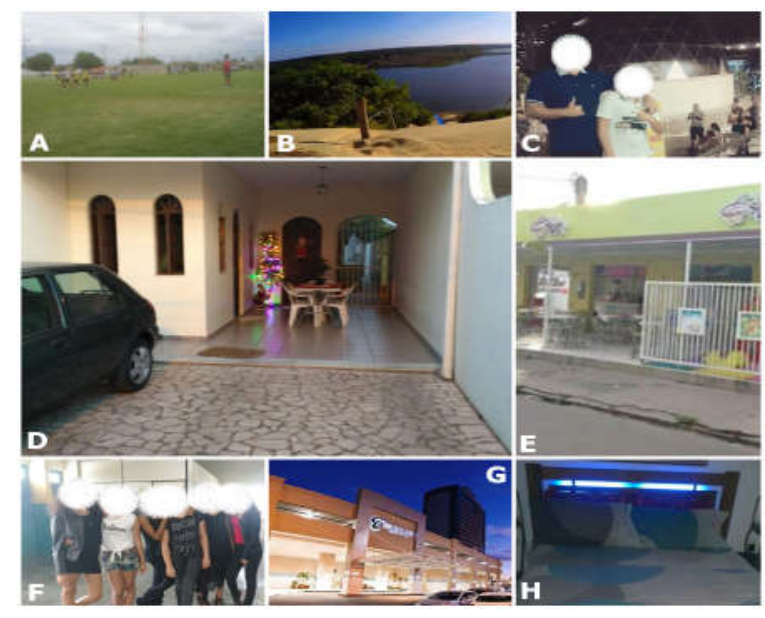

Figura 1. Mosaico das fotografias produzidas pelos sujeitos pesquisados - turma1 
Ao analisar as fotografias da turma 1, observou-se que nas fotografias A, B e C os alunos não trazem Feira de Santana como seus lugares e sim outros locais onde estiveram com a família e/ou que vão no final de semana, a exemplo da foto A, ou seja, lugares de lazer guardando com estes uma relação de afetividade. As demais fotografias são de Feira de Santana, apresentando lugares de vivência e de suas relações, as fotografias D e H representam a casa e o quarto respectivamente, onde sentem-se à vontade e seguras; já as fotografias E (Lanchonete o "MilkShake"), F (a escola), e G (O shopping) traduzem a ideia de lugar como espaço de lazer e de divertimento.

Turma 2 - De acordo com as respostas dos questionários, notou-se que os alunos entendiam por lugar um espaço apropriado para a vida, onde se vive, onde as pessoas se conhecem e se sentem bem em que as pessoas se identificam e se sentem seguros. Todos os alunos afirmaram ter uma boa relação com Feira de Santana tanto que a maioria das fotografias (figura 2) trazem a cidade materializados em suas casas como seus lugares, ou seja, a fotografia confirmou a ideia trazida pelo questionário.

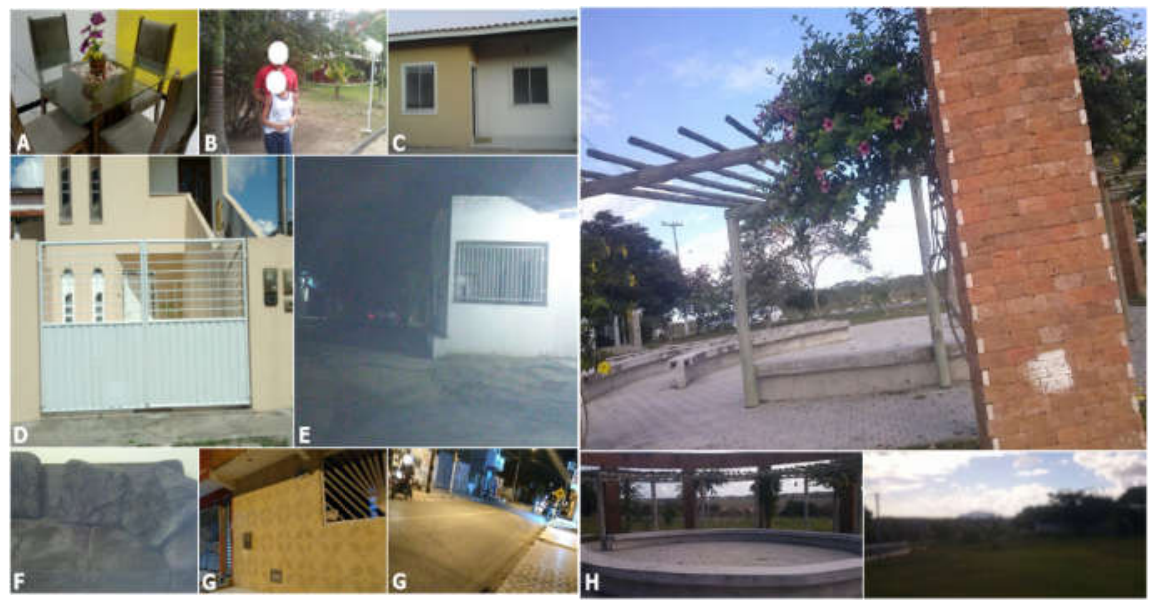

Figura 2. Mosaico das fotografias produzidas pelos sujeitos pesquisados - turma2

As fotografias A (mesa das refeições), B (casa da aluna), C (casa do aluno), D (fachada da casa), E (frente da casa), F (sofá) e G (rua em frente à casa do aluno),apresentam o lugar como o espaço vivido por eles, ou seja, relacionaram a ideia de lugar através de suas casas ou cômodos destas.A fotografia $\mathrm{H}$ (praça) que não se refere ao espaço da casa, mas sim um lugar remetido ao lazer pelo aluno. Nota-se com isso, que os alunos trazem suas casas para demonstrar que é nestas, que se sentem bem, onde se identificam e é onde estão próximos de seus familiares. É fundamental destacar ainda, que os alunos levaram em consideração os elementos essenciais (como o enquadramento, corte numa foto) para se tirar uma boa fotografia, cuidando da construção do olhar o que reforçou a importância da oficina na intervenção. Portanto as perspectivas de Carlos (1995) e Tuan (1983) auxiliam para explicar o lugar dos sujeitos da pesquisa, que grande parte destes, traduz e materializam seus lugares através do espaço vivido

\section{CONCLUSÃO}

A escola é um local, por excelência, responsável por fazer o aluno pensar sobre o espaço em que está inserido. Assim, as metodologias de ensino que levem o aluno a construir o seu conhecimento através da sua vivência são importantes para se atingir este objetivo. A fotografia entra na discussão como um recurso capaz de provocar no aluno sua sensibilidade, 
curiosidade e também criticidade sobre o que está sendo observado, mas, para tal, é necessário ensinar o aluno a olhar.

A experiência da discussão do olhar e uso da fotografia como metodologia e material didático foi bastante positiva, pois percebeu-se como os sujeitos puderam dar outro significado às fotografias trazendo seus lugares como foco. Com isso, a discussão do conceito se tornou atraente e diferente apresentando mais sentido aos conteúdos estudados e maiores relacionamentos entre os mesmos e a vida dos estudantes.

\section{REFERÊNCIAS}

CARLOS, Ana Fani A. O lugar no/do mundo. Encontro Nacional de Pós-Graduação em Geografia. Aracajú. 1995.

DUBOIS, Philipe. O ato fotográfico e outros ensaios. Editora: papiros. $8^{\mathrm{a} e d . ~ S a ̃ o ~ P a u l o, ~}$ 1993.

SAMAIM, Etienne. O fotográfico. 2a ed. Editora: Senac. São Paulo, 2005.

Acessos em 24/25/26/27 e 28 de fevereiro de 2017

TUAN, Yi-Fu. Espaço e lugar: a perspectiva da experiência. São Paulo: Difel, 1983.

Acessos em 24/25/26/27 e 28 de fevereiro de 2017: 